\title{
64. Inherited Functional Alterations in the Hypothalamo-Pituitary-Thyroid System in Rats raised from Thyroidectomized Mothers
}

\author{
By Tomoko FUJII, Nobuko Yamamoto, Yoshimi Shirakura, \\ and Tadashi Komura \\ Department of Pharmacology, Teikyo University \\ School of Medicine, Itabashi, Tokyo 173
}

(Communicated by Setsuro EBASHI, M. J. A., May 13, 1985)

We have reported that maternal parathyroidectomy in the rat during pregnancy affects the functional development of calcium regulatory system in the offspring over several generations. Less marked hypocalcemic response to the removal of parathyroid glands was observed in the 3rd or 4th generation offspring as well as in the first generation offspring when mother rats were parathyroidectomized on the 5th day of gestation. ${ }^{7}$ ) A delay of reproductive aging in the descendants of the parathyroidectomized mother was noted for several generations. ${ }^{10)}$ When mother rats were parathyroidectomized on the 15 th day of gestation, the offspring rats showed a decreased threshold to the lethal dose of calcium chloride over 10 generations.9) These results provide evidence showing considerably large influence of maternal environment on the phenotypic expression in fetuses.

Thyroid hormones are well known to play a crucial role in the development of human and animals. However, because of that the available information from human and animal studies have indicated a limited transfer of thyroid hormones either from mother to fetus or from fetus to mother, ${ }^{4)}$ the effect of maternal thyroid disorders on the functional development of fetuses have been inadequately studied. We report here that maternal thyroidectomy during pregnancy resulted in alterations in the hypothalamo-pituitary-thyroid function in the sequential offspring.

Materials and methods. Wistar-Imamichi male and female rats were mated and the day on which sperm was present in the vaginal smear was designated as day 0 of pregnancy. The pregnant rats were surgically thyroidectomized ( $\mathrm{Tx})$ under ether anesthesia on the 5th day of gestation and $1 \%$ calcium chloride solution was given as drinking water until the time of weaning. Control pregnant rats were sham-operated. Tx mothers delivered normally on the $22 \mathrm{nd}$ day of gestation. Litter-size of the Tx rats did not differ from that of controls. All pups were weaned at 21 days of age. The subsequent generation offspring rats were developed by sister-brother mating. The second $\left(\mathrm{F}_{2}\right)$ and third $\left(\mathrm{F}_{3}\right)$ generation rats of Tx or sham-operated groups were thyroidectomized at 3 months of age. They were killed by decapitation 1, 2, 3 or 7 days after the operation and the trunk blood was collected. In another series of experiments, the shamand $\mathrm{Tx}-\mathrm{F}_{4}$ rats were tested for pituitary thyrotropin(TSH) response to synthetic thyrotorpin-releasing hormone(TRH) administration. Blood samples of the sham- and $\mathrm{Tx}-\mathrm{F}_{4}$ rats were obtained from the jugular vein by venipuncture with 26-G needle for determination of the basal TSH level. These animals were then divided into two groups; one group was injected intravenously with $5 \mu \mathrm{g} / \mathrm{kg}$ 
of synthetic TRH (Peptide Institute Inc., Osaka) dissolved in saline to give an injection volume of $1 \mathrm{ml} / \mathrm{kg}$ and the other group with saline alone to serve as controls. The rats were killed by decapitation 5, 15 or 30 min later and the trunk blood was collected. Isolated serum was kept frozen at $-20^{\circ} \mathrm{C}$. Serum TSH was measured by the double antibody radioimmunoassay ${ }^{20}$ ) using the rat pituitary hormone kit provided by the National Pituitary Agency, NIAMDD. The standard used was NIAMD-Rat TSH-RP1. Serum thyroxine $\left(\mathrm{T}_{4}\right)$ was measured using a radioimmunoassay (Spac ${ }^{\mathrm{TM}}$, Dai-ichi Radioisotope Lab., Tokyo). The rats were kept in a temperature-controlled room $\left(22 \pm 3{ }^{\circ} \mathrm{C}\right)$ with a lighting schedule of $14 \mathrm{hr}$ light $(06: 00-20: 00)$ and $10 \mathrm{hr}$ darkness and supplied with a stock diet (Oriental Yeast Co., Ltd.) and water ad libitum. Statistical analyses of data were performed using Student's $t$-test.

Results. There was no significant difference in the body growth, basal serum $\mathrm{T}_{4}$ and TSH levels between the sham- and Tx-offspring rats. Serum TSH levels in both male and female rats of the sham $-\mathrm{F}_{2}$ groups showed a significant increase from the basal level $(\mathrm{P}<0.05) 24 \mathrm{hr}$ after thyroidectomy and the level continued to increase until the 7 th day of the operation examined. In the $T x-F_{2}$ male rats, serum TSH levels showed a significant increase $24 \mathrm{hr}$ after thyroidectomy, but it reached a plateau on the 2nd to 3rd day of the operation and no further increase was observed on the 7th day, i.e., the TSH level on the 7 th day was significantly lower than that in the sham- $F_{2}$ males $(\mathrm{P}<0.01)$ (Fig. 1).

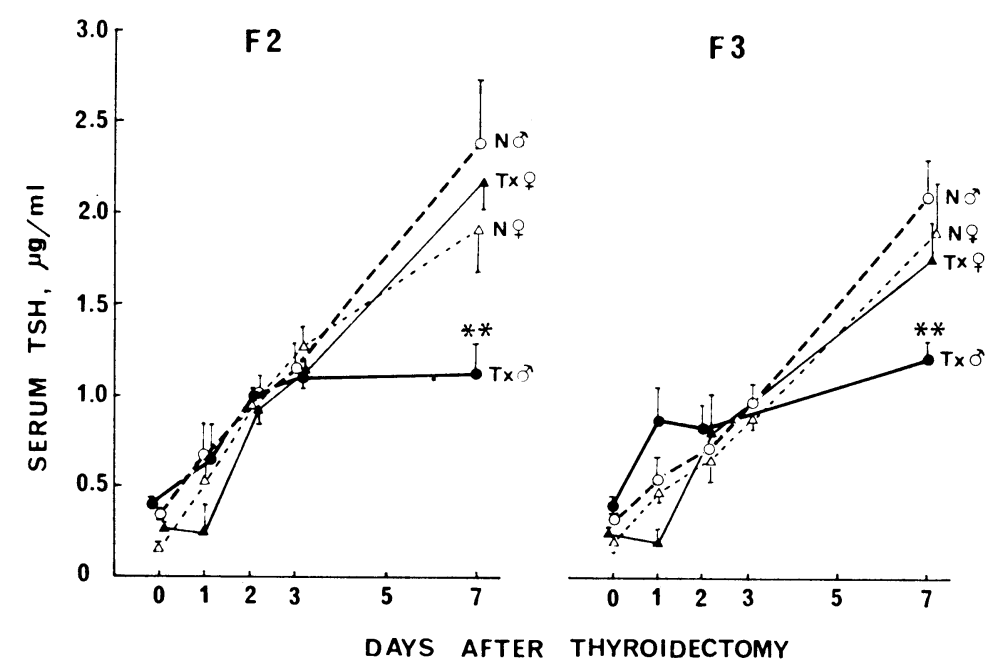

Fig. 1. Serum TSH levels following thyroidectomy in the second $\left(\mathrm{F}_{2}\right)$ or third $\left(\mathrm{F}_{3}\right)$ generation rats raised from sham-operated $(\mathrm{N})$ or thyroidectomized (Tx) mothers. ** $\mathrm{P}<0.01$ vs. $\mathrm{N}$ males.

Serum TSH levels in the Tx- $\mathrm{F}_{2}$ female rats did not increase $24 \mathrm{hr}$ after thyroidectomy but showed a significant progressive increase to the same level as in the sham- $\mathrm{F}_{2}$ females on the $2 \mathrm{nd}, 3 \mathrm{rd}$ and 7 th day of thyroidectomy. Thyroidectomy in the sham $-\mathrm{F}_{3}$ male and female rats also resulted in a progressive increase in serum TSH levels. Its changing pattern was similar to that shown in the sham $-\mathrm{F}_{2}$ rats. As shown in the $\mathrm{Tx}-\mathrm{F}_{2}$ male rats the $\mathrm{Tx}-\mathrm{F}_{3}$ male rats also showed a less marked increase in serum TSH levels 7 days after thyroidectomy; the 
level was significantly lower than that in the sham- $\mathrm{F}_{3}$ males $(\mathrm{P}<0.01)$ (Fig. 1). The $\mathrm{Tx}-\mathrm{F}_{3}$ female rats responded to thyroidectomy with no increase in serum TSH levels at $24 \mathrm{hr}$ and then with a progressive increase toward the same level in the sham- $\mathrm{F}_{3}$ control females on the 7 th day of the operation. This changing pattern in the serum TSH level was quite similar to that in the Tx- $\mathrm{F}_{2}$ females.

Table I. Serum TSH levels $(\mu \mathrm{g} / \mathrm{ml}$ serum) following an intravenous injection of synthetic TRH $(1 \mu \mathrm{g} / \mathrm{kg})$ in the 4th generation rats raised from sham-operated or thyroidectomized $(\mathrm{Tx})$ mothers

\begin{tabular}{|c|c|c|c|c|}
\hline \multirow{2}{*}{$\begin{array}{l}\text { Time after } \\
\text { TRH (Min) }\end{array}$} & \multicolumn{2}{|c|}{ Male } & \multicolumn{2}{|c|}{ Female } \\
\hline & Control & $\mathrm{Tx}$ & Control & $\mathrm{Tx}$ \\
\hline 0 & $0.153 \pm 0.040 *$ & $0.125 \pm 0.015$ & $0.132 \pm 0.010$ & $0.126 \pm 0.024$ \\
\hline 5 & $1.087 \pm 0.191$ & $0.740 \pm 0.115$ & $0.944 \pm 0.185$ & $0.902 \pm 0.056$ \\
\hline 15 & $2.081 \pm 0.135$ & $1.385 \pm 0.193 * \%$ & $1.319 \pm 0.258$ & 1. $467 \pm 0.475$ \\
\hline 30 & 1. $224 \pm 0.096$ & $0.896 \pm 0.138^{*}$ & $0.598 \pm 0.067$ & $0.913 \pm 0.152^{*}$ \\
\hline
\end{tabular}

* Mean \pm SEM. Number in parentheses indicate the number of rats examined.

A single intravenous injection of $5 \mu \mathrm{g} / \mathrm{kg} \mathrm{TRH}$ to the sham- $\mathrm{F}_{4}$ and $\mathrm{Tx}-\mathrm{F}_{4}$ offsprings induced a marked increase in serum TSH levels. The maximal increase was shown 15 min after the injection of TRH in male and female rats of both groups. However, the magnitude of the increase in serum TSH levels in the $\mathrm{Tx}-\mathrm{F}_{4}$ male rats was significantly lower than that in sham- $\mathrm{F}_{4}$ male rats (Table I).

Discussion. The present results clearly indicated that the offspring rats, particularly male offspring, raised from mothers thyroidectomized on the 5th day of gestation possess heritable deficits in the hypothalamo-pituitary-thyroid function. In the $T x-F_{2}, F_{3}$ and $F_{4}$ generation male rats, the responsiveness of the hypothalamo-pituitary axis to the deprivation of thyroid hormones or to exogenous TRH administration showed a marked decline. It has been observed in human and animals that thyroidectomy results in an increase in the release of TRH from the hypothalamus and of TSH from the pituitary gland via negative feedback mechanism. The decreased release of TSH in response to thyroidectomy or to TRH administration observed in the present experiments might suggest a decrease in (1) pituitary TRH receptors, (2) TRH concentrations released into the portal circulation, or (3) TSH synthesis in thyrotrophs. Although mechanisms involved in the present findings including sex difference in the effect of maternal thyroidectomy are unknown, the decreased TSH response to exogenous TRH stimulation which is demonstrated in the Tx- $F_{4}$ male rats may suggest alterations of thyrotrophs. TRH crosses the placenta in rats ${ }^{11}$ ) and presumably in human. But the palcenta is essentially impermeable to TSH and thyroxine and triiodothyronine., ${ }^{4,15)}$ Moreover, it has been indicated that the fetal hypothalamo-pituitary-thyroid system develops and functions largely independent of maternal system. ${ }^{5}$ However, maternal hypothyroidism has been known to induce a certain change in fetal development or in fetal pituitarythyroid function in human ${ }^{14)}$ or in rats. ${ }^{17), 18)}$ The present results also indicated that maternal thyroid function is of an extreme importance for the functional 
development of fetal hypothalamo-pituitary-thyroid system. Animal studies have shown increased responsiveness of the pituitary-thyroid system to TRH or to thyroxine during pregnancy. ${ }^{12)}$ This suggests that thyroidectomy during pregnancy would result in an expanded alterations in the hypothalamo-pituitary-thyroid system.

There are still a few reports on the vertical transmission of altered phenotypic expression in the progeny affected by maternal environment. As mentioned above, maternal parathyroid ablation induces alterations in the regulatory system of serum calcium or in the threshold to calcium itself in the offspring for several generations in the rat.7),9),10) When neonatal female rats were made hypothyroid with large doses of thyroxine and mated to normal males, their $F_{1}$ and $F_{2}$ offspring showed a variety of abnormal endocrine functions. ${ }^{1)}$ Maternal undernutrition results in cerebral deficiency ${ }^{21)}$ or in immune-deficiency ${ }^{3)}$ for several generations. Maternal zinc deprivation in mice has been found to induce deficiency of antibody formation in the $\mathrm{F}_{2}$ and $\mathrm{F}_{3}$ generation offspring. ${ }^{2)}$ Effects of parental exposure to drugs also results in heritable functional alterations in the offspring over several generations. Behavioral changes in the $F_{2}$ or $F_{3}$ generation offspring of mice or rats treated with morphine, ${ }^{6}$ ) 6 -mercaptopurine, ${ }^{19}$ ) phenytoin $^{8)}$ or tricyclic antidepressants ${ }^{13}$ ) have been reported. Transmission of tumor incidence into the 3rd generation offspring of mice exposed to urethan or radiation has been observed by Nomura. ${ }^{16)}$ The present results would extend a new sight into maternal hypothyroidism as a factor which modifies phenotypic expression in offspring, though the mechanism remains unsolved.

Acknowledgements. We are grateful to Dr. A. F. Parlow, Harbor General Hospital, Torrance, California and to the National Institute of Arthritis and Metabolic Diseases, The Rat Pituitary Hormone Program, for the generous supply of radioimmunoassay kits. We thank Dr. K. Wakabayashi for his help in measurements of TSH.

\section{References}

1) Bakke, J. L. et al.: Biol. Neonate, 31, 71-83 (1977).

2) Beach, R. S. et al.: Science, 218,469-471 (1982).

3) Chandra, R. K.: ibid., 190, 289-290 (1975).

4) Fisher, D. A.: Perinatal Thyroid Physiology and Disease (eds. D. A. Fisher and G. N. Burrow). Raven Press, New York, pp. 21-32 (1975).

5) Fisher, D. A. et al.: Recent Progr. Hormone Res., 33, 59-116 (1977).

6) Friedler, G.: Perinatal Pharmacology: Problems and Priorities (eds. J. Dancis and J. C. Hwang). Raven Press, New York, pp. 207-219 (1974).

7) Fujii, T.: Nature, 273, 236-238 (1978).

8) Fujii, T. et al.: Proc. Japan Acad., 58B, 78-82 (1982).

9) Fujii, T. et al.: ibid., 59B, 105-107 (1983).

10) Fujii, T., and Yamamoto, N.: Exptl. Aging Res., 9, 129-133 (1983).

11) Kajihara, A. et al.: Endocrinology, 90, 592-594 (1972).

12) Kojima, A. et al.: ibid., 95, 599-605 (1974).

13) Maj, J.: Pol. J. Pharmacol. Pharm., 32, 437-449 (1980).

14) Man, E. B.: Perinatal Thyroid Physiology and Disease. (eds. D. A. Fisher and G. N. Burrow). Raven Press, New York, pp. 117-132 (1975).

15) Nathanielsz, P. W.: Monographs in Fetal Physiology. vol. 1, Fetal Endocrinology, An Experimental Approach. North-Holland Publishing Co., Amsterdam, pp. 73$87(1976)$.

16) Nomura, T.: Cancer Res., 35, 264-266 (1975).

17) Porterfield, S. P. et al.: Proc. Soc. Biol. Med., 149, 748-753 (1975).

18) Porterfield, S. P., and Hendrich, C. E.: Endocrinology, 108, 1060-1063 (1981).

19) Reimers, T. J., and Sluss, P. M.: Science, 201, 65-67 (1978).

20) Wakabayashi, K. et al.: Gunma Symp. Endocrinol., 12, 65-86 (1975).

21) Zamenhof, S., and Van Marthens, E.: J. Nutr., 108, 1719-1723 (1978). 